\title{
CARBONIZED PARYLENE AS A CONFORMAL SACRIFICIAL LAYER
}

\author{
Elliot E. Hui", Chris G. Keller ${ }^{+}$, and Roger T. Howe ${ }^{* *}$ \\ Depts. of EECS*, MSME ${ }^{+}$, and $\mathrm{ME}^{*}$ \\ Berkeley Sensor \& Actuator Center \\ University of California at Berkeley \\ Berkeley, CA 94720-1774
}

\begin{abstract}
This paper describes a conformal carbon sacrificial layer process with application to molded polysilicon structures. Molded structures $25 \mu \mathrm{m}$ tall have been fabricated and released using a sacrificial layer only $0.3 \mu \mathrm{m}$ thick. Parylene is deposited from the vapor phase as a conformal film. After a pre-treatment in a plasma of $\mathrm{CHF}_{3}$ and $\mathrm{He}$ to cross link its surface, the parylene is pre-baked at $400{ }^{\circ} \mathrm{C}$ and then heated in an $\mathrm{N}_{2}$ ambient at $700-1000{ }^{\circ} \mathrm{C}$ to form a conformal layer of carbon. Following conventional deposition, annealing, and patterning of the polysilicon structural film, the carbon sacrificial layer is removed by oxidation. At $700^{\circ} \mathrm{C}$, the oxidation rate is as high as $50 \mu \mathrm{m} / \mathrm{min}$ for the first 2000 $\mu \mathrm{m}$ of undercut.
\end{abstract}

\section{INTRODUCTION}

Surface micromachining is dependent on highly selective removal of sacrificial layers with minimal attack of either the structural layers or the isolation films used to protect the substrate [1]. Silicon dioxide is a common sacrificial layer for polysilicon and silicon nitride microstructures, with hydrofluoric acid being used as the selective etch for oxide. There are several drawbacks with deposited oxide sacrificial layers for molded polysilicon processes (Hexsil) [2], which demand highly conformal film coverage and can involve very long etches in concentrated HF to remove oxide films coating a complex, deep-etched mold.

In order to achieve a precision replication of the mold, a thin, uniform sacrificial layer is needed. Conformal $\mathrm{SiO}_{2}$ films can be deposited using tetraethylorthosilicate (TEOS) as a precursor [3]. For faster etching, phosphorus-rich sacrificial layers are desirable, however, such PSG films tend to deposit less conformally [4]. In order to ensure that the mold is adequately coated by a less conformal sacrificial layer, thicker depositions are required.

The wet etching of $\mathrm{SiO}_{2}$ sacrificial layers has been extensively studied [5]. Lengthy undercuts, such as those needed for releasing Hexsil molded parts, translate into very long etch times due to the slow etch rate and ultimately, due to diffusion effects. Wet release processes are also prone to stiction of the released structures after drying due to capillary forces [6]. Hexsil molded structures, with their large surface areas, are especially vulnerable to this phenomenon. Finally, it has been conjectured that long exposure to HF during the sacrificial oxide etch can damage polysilicon structural films, through attack at the grain boundaries or other mechanisms [7-9]. A recent study suggests pitting from HF attack as one cause of the large spread in polysilicon fracture stress [10].

Carbon as an altemative sacrificial layer was pioneered by J. Bernstein over a decade ago and applied to sheet polysilicon fabrication for solar cells [11]. A principal advantage of carbon is that it can be etched with extremely high selectivity with respect to inorganic materials such as silicon, oxides, or nitrides by simple oxidation - a dry process. Oxidation of carbon can be a very rapid

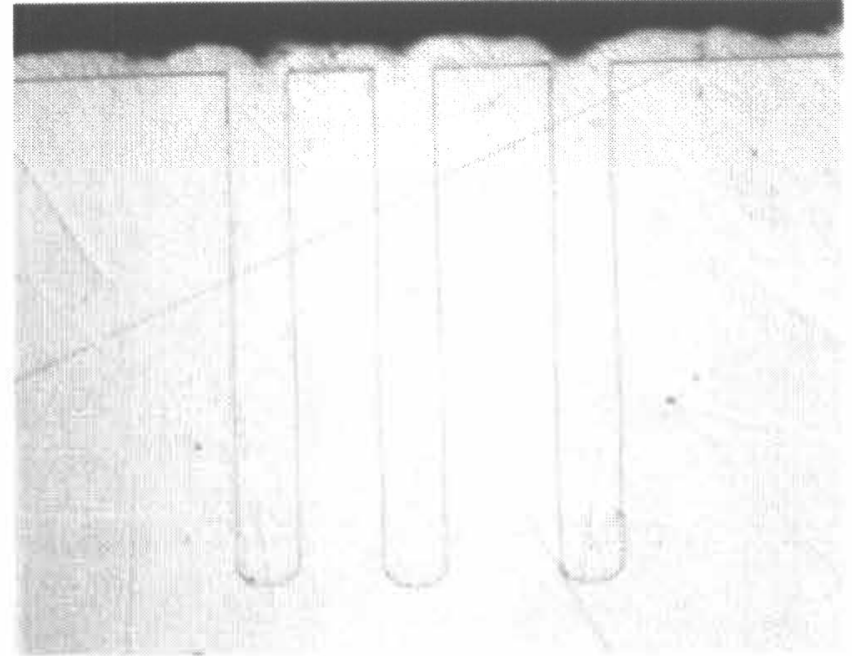

Figure 1. $50 \mu \mathrm{m} \times 8 \mu \mathrm{m}$ trenches lined with a $0.3 \mu \mathrm{m}$ carbon sacrificial layer and filled with molded LPCVD polysilicon.

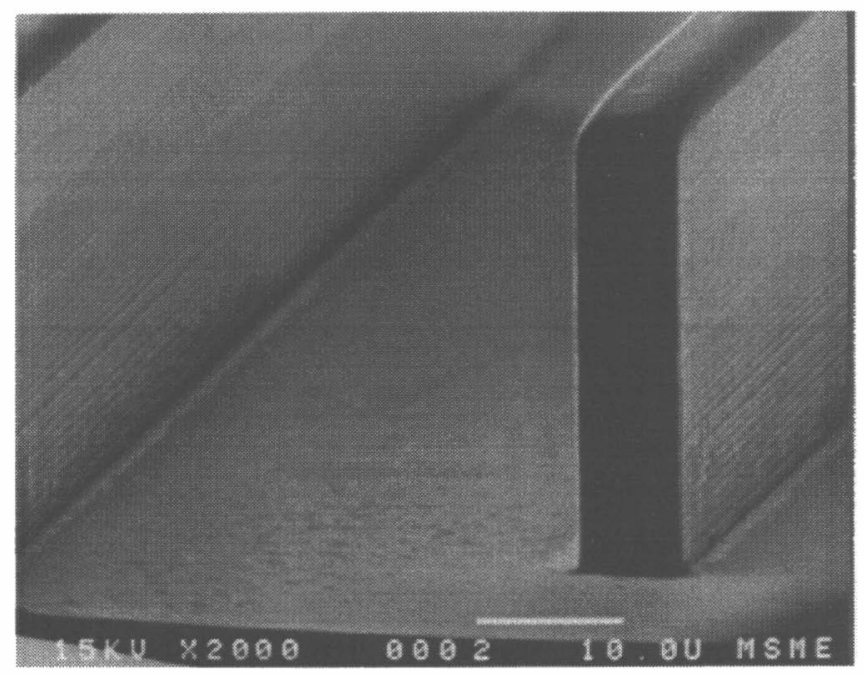

Figure 2. A 25- 4 m tall polysilicon fin, molded and released using a 0.3- $\mathrm{m}$ carbon sacrificial layer. The lines on the sidewalls are an accurate representation of the mold, which has scalloping on walls caused by the deep RIE etcher.

process at moderate temperatures, which, together with the nearinfinite selectivity, implies that large areas of polysilicon can be undercut. Polysilicon nucleation on carbon films was also found to be superior to that on oxide films [11].

In order to extend the carbon process to the conformal sacrificial layers needed for molded polysilicon microstructures, this paper characterizes processes for carbonizing a conformally deposited parylene film. A critical step is the stabilization of the parylene against flow while heating to temperatures of $700-1000^{\circ} \mathrm{C}$ 
in $\mathrm{N}_{2}$ during carbonization, which we have achieved to a large degree using a plasma treatment and pre-bake. After describing the formation of the carbon sacrificial layer, its initial application to the fabrication of Hexsil test structures is outlined

As can be seen from the lapped cross section in Fig. 1 and the SEM of a released polysilicon fin in Fig. 2, carbonized parylene approaches the ideal thin and conformal sacrificial layer. Sidewall features on the released polysilicon fin replicate the scalloped surface of the silicon mold with good fidelity, owing to the 0.3 um-thick conformal carbon sacrificial layer. Oxidation at $700^{\circ} \mathrm{C}$ was used to etch the carbon and release the polysilicon part.

\section{BASIC PROCESS}

\section{Carbon Preparation}

Formation of the carbon film involves deposition of parylene, hardening of the parylene surface, and finally carbonization of the parylene by heating in the absence of $\mathrm{O}_{2}$. Parylene polymers are vapor deposited at low pressure at room temperature. Prior to deposition, an adhesion layer of A-174 Silane is applied to the silicon mold wafer. $2-\mu \mathrm{m}$ coatings of Parylene $\mathrm{C}$ (poly 2-chloro-paraxylene) were used in this work.

Hardening of the parylene surface is needed in order to prevent flow of the parylene during the high temperature carbonization step. Currently, the most effective hardening step consists of a 1-minute exposure to a $100-\mathrm{W}$ plasma of $\mathrm{CHF}_{3}$ and $\mathrm{He}$, followed by a pre-bake in $\mathrm{N}_{2}$. For the pre-bake, the furnace temperature is ramped from room temperature up to $400{ }^{\circ} \mathrm{C}$ and then immediately turned off and allowed to cool back down to room temperature.

Heating to $700-1000{ }^{\circ} \mathrm{C}$ completes carbonization. Care must be taken not to expose parylene or carbon to oxygen while at high temperature. Samples are inserted into a furnace tube at room temperature. After sealing and purging the tube with nitrogen gas, the furnace is ramped up to the desired temperature. One hour at the elevated temperature has been found to be sufficient for carbonization. The furnace tube is then allowed to cool to room temperature before the samples are removed. The thickness of the resulting carbon layer is reduced by factor of four from that of the originally deposited parylene.

The polysilicon structural layer is deposited and annealed conventionally. Inserting samples into the LPCVD tube at around $600{ }^{\circ} \mathrm{C}$ has not been found to adversely affect the carbon even though oxygen is present to some extent during insertion. Piranha and HF cleaning also do not harm the carbon. Patterning of the structural layer should be straightforward, although we have not attempted this yet.

Oxidation burnout for release is performed with dry $\mathrm{O}_{2}$ in a furnace tube. The oxidation temperature currently used is $700^{\circ} \mathrm{C}$.

\section{Process Characterization}

To examine the application of the carbon sacrificial layer to Hexsil technology, high aspect ratio trench structures were fabricated using anisotropic $\mathrm{KOH}$ etching of (110) silicon. Trenches were $200 \mu \mathrm{m}$ deep and $4-16 \mu \mathrm{m}$ wide, as shown in Fig. 3(a). Hexsil molds were also prepared using deep RIE.

In order to observe the conformality of the parylene deposition, coated trench structures were dipped in liquid nitrogen to freeze the parylene film and then immediately cleaved for crosssectional SEM imaging.

Coated test structures were carbonized following a variety of pre-treatments in order to characterize the effect of various prebake temperatures as well as the presence or absence of different
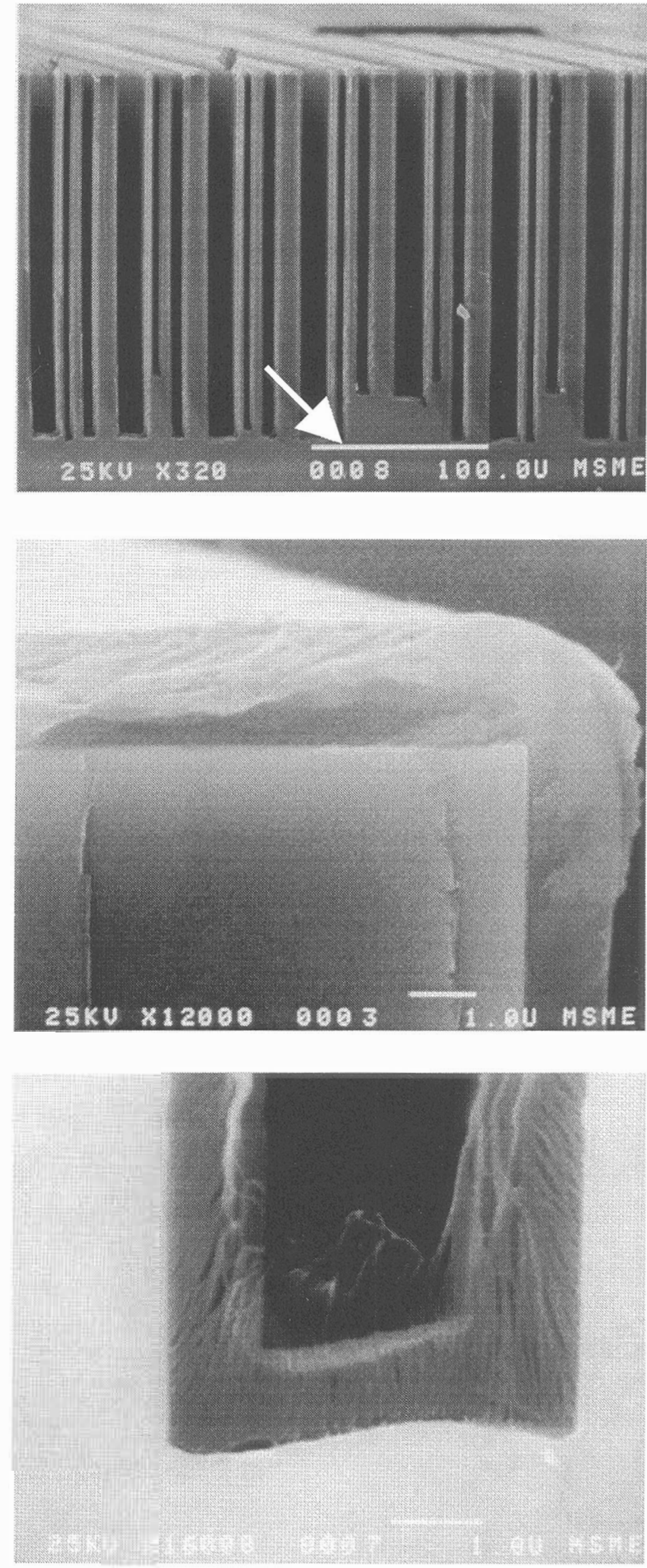

Figure 3. (a) Cross-sectional view of high aspect ratio test structures, $200 \mu \mathrm{m}$ deep and $4-16 \mu \mathrm{m}$ wide, coated with parylene. The arrow indicates the location of $3(c)$. (b) Close-up view of a corner shows that the parylene step coverage is excellent.

(c) Coverage is also very good at the bottom of a trench. The wispy strings are an artifact of sample preparation, in which the ductile parylene was frozen in liquid nitrogen prior to cleaving the wafer. 

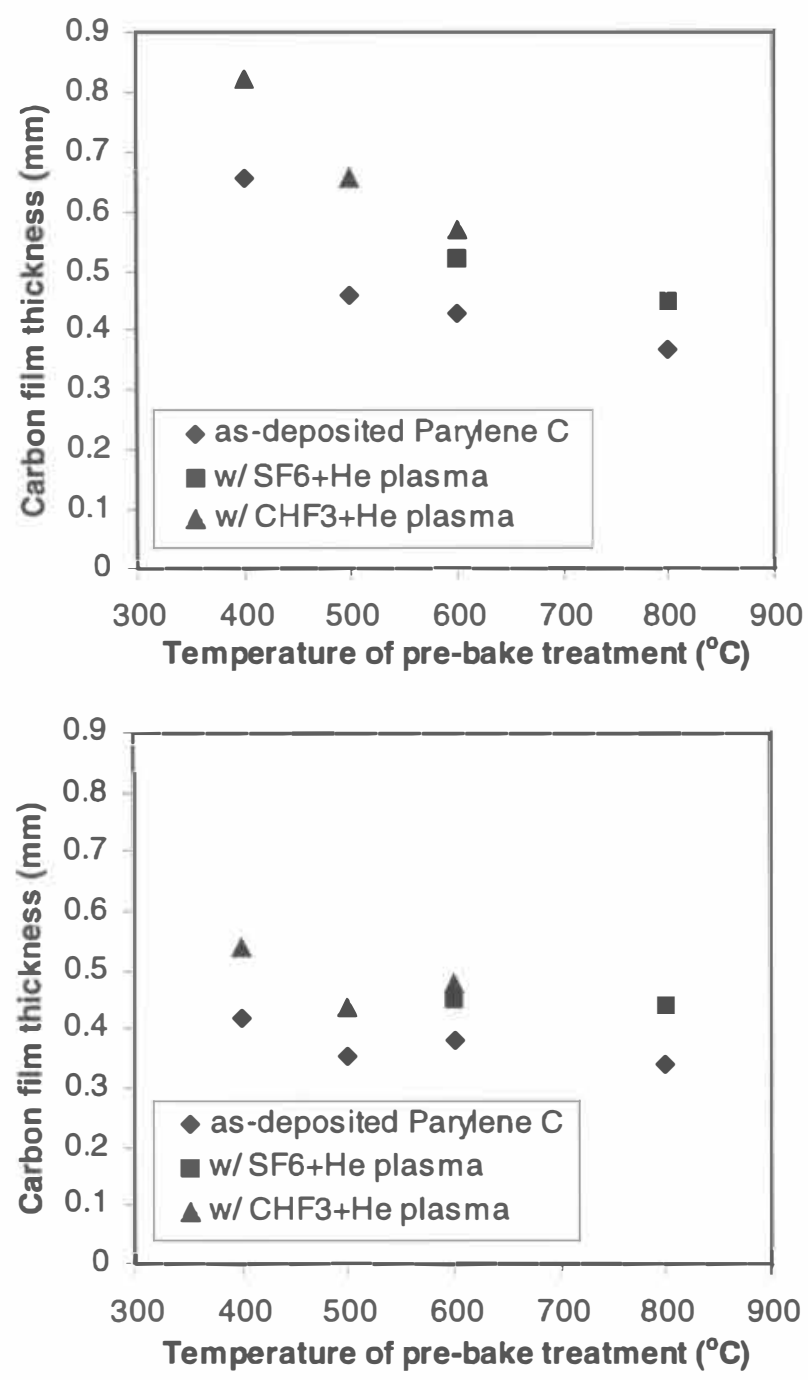

Figure 4. (a) Thicknesses of parylene/carbon films following various combinations of plasma and pre-bake pre-treatments before carbonization, and (b) after carbonization. The $400^{\circ} \mathrm{C}$ prebake and $\mathrm{CHF}_{3}$ and He plasma give the greatest carbon yield.

plasmas. Changes in film thickness were monitored by measuring the step height at an edge of the film with a profilometer. The film edge was created by scratching off a portion of the deposited parylene using a razor blade. Carbon coatings on trench structures were examined by cleaving the wafer and examining the cross section by a SEM.

To measure the oxidation-undercut rate, a carbon film on a plain wafer was coated with polysilicon, and then part of the wafer was cleaved to expose the carbon at one edge. Samples were inserted directly into the oxidation furnace tube at $700{ }^{\circ} \mathrm{C}$. At the end of the desired oxidation period, the samples were directly removed from the hot furnace and the undercut distance was measured with an optical microscope.

The etch rate of carbon in an $\mathrm{O}_{2}$ plasma was also measured. In this case, the carbon was directly exposed to the plasma instead of being burned out from underneath a polysilicon layer. Film thickness was measured with a profilometer as described above.

Finally, AFM and water contact angle measurements were performed on released polysilicon. The surface of interest was that which had previously been in contact with the carbon.

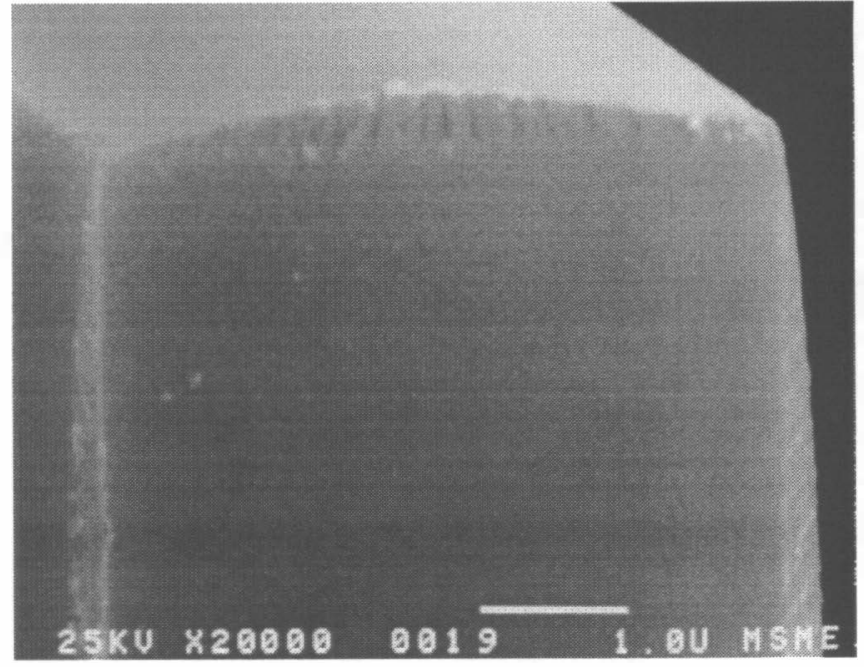

Figure 5. As-deposited parylene flows during the carbonization process, leading to poor corner coverage.

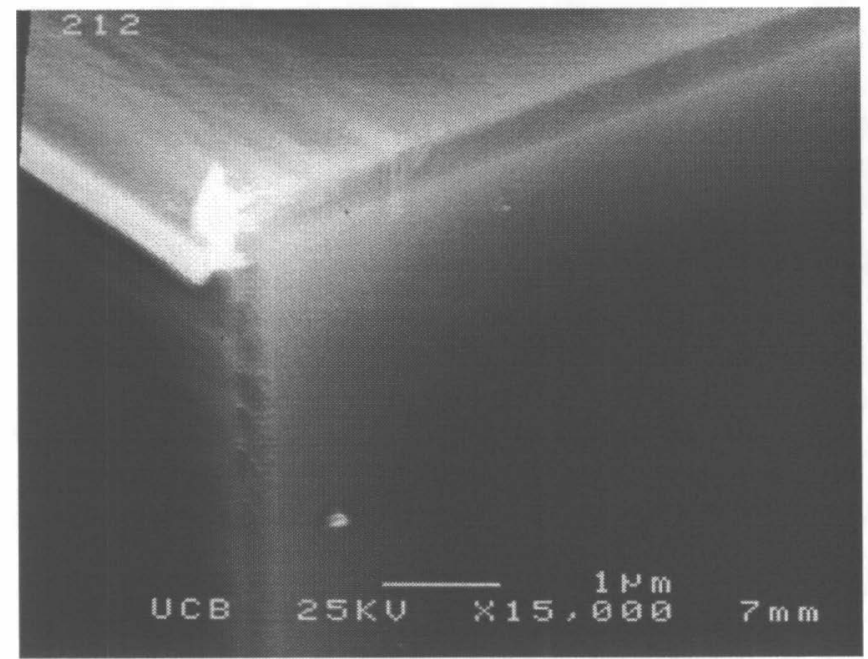

Figure 6. Pre-treating the parylene with a plasma-hardening step and a low-temperature pre-bake results in a much more conformal film at convex corners after carbonization

\section{RESULTS AND DISCUSSION}

Parylene was found to deposit extremely conformally, as shown in Fig. 3. Corner coverage is very good. However, the coating is not perfectly uniform but instead becomes slightly thinner going down deep and narrow trenches. This may be a result of loading.

Carbonization reduces the polymer film thickness by roughly a factor of four, which is not unusual in the carbonization of polymers [12]. Fig. 4 shows that proper pre-treatment can significantly increase the total carbon yield. The best result found was the use of a $\mathrm{CHF}_{3}$ and $\mathrm{He}$ plasma combined with a $400{ }^{\circ} \mathrm{C}$ prebake, resulting in a final carbon thickness of $0.54 \mu \mathrm{m}$.

Significant reflow was found to occur during carbonization of as-deposited parylene. Fig. 5 shows the poor corner coverage that results. The film in Fig. 6 was carbonized after receiving the pre-treatment described above and shows much better conformality. A side-effect of the plasma treatment is that the crosslinked crust wrinkles slightly as the film volume decreases during carbonization. Sometimes a lip can even develop at 


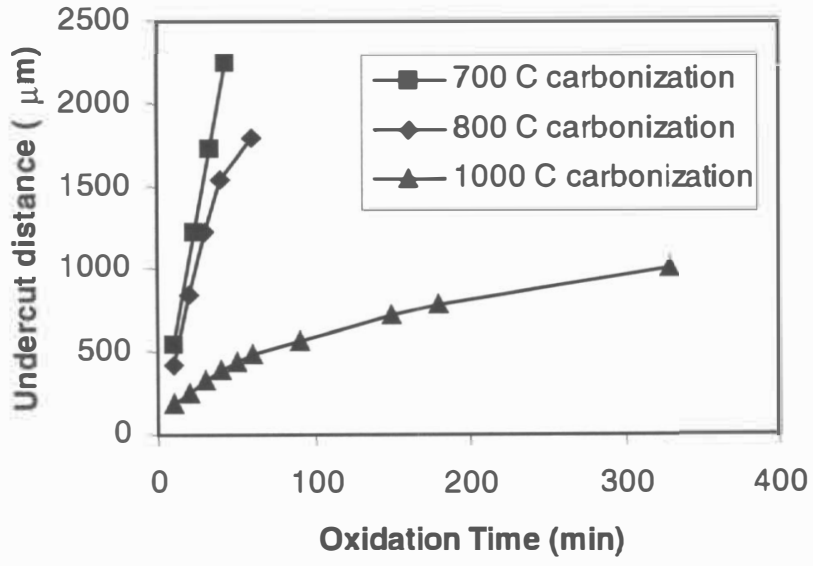

Figure 7. Distance of undercut as a function of time as carbon is being oxidized out from underneath a sheet of polysilicon at a temperature of $700{ }^{\circ} \mathrm{C}$. Note that carbon prepared at lower carbonization temperatures oxidizes faster.

corners. The lip should be easy to remove with a light $\mathrm{O}_{2}$ plasma etch.

Fig. 7 shows the oxidation-undercut rate of carbon at an oxidation temperature of $700{ }^{\circ} \mathrm{C}$. The oxidation rate is very rapid - as high as $50 \mu \mathrm{m} / \mathrm{min}$ for the carbon prepared at a carbonization temperature of $700{ }^{\circ} \mathrm{C}$. The oxidation rate slows significantly for films carbonized at higher temperatures, indicating that some change in carbon structure occurs at higher temperatures of carbonization. It is interesting to note that all three samples were annealed at $1000{ }^{\circ} \mathrm{C}$ for 1 hour following the polysilicon deposition, and yet the carbon prepared at lower temperatures still oxidized more easily. Note also that there were other variations besides carbonization temperature in the preparation of the three samples and so the ratios of etch rates for the three types of carbon cannot be determined exactly from this data.

The etch rate of carbon in an $\mathrm{O}_{2}$ plasma was found to be 0.1 $\mu \mathrm{m} / \mathrm{min}$ at $100 \mathrm{~W}$ and $0.2 \mu \mathrm{m} / \mathrm{min}$ at $300 \mathrm{~W}$.

The underside surface was found to be hydrophilic, with a water contact angle of $16^{\circ}$. Underside roughness measurements of the released polysilicon $\left(580{ }^{\circ} \mathrm{C}, 300 \mathrm{mT}\right.$ deposition), obtained using an AFM, showed a surface roughness of $1.4 \mathrm{~nm} \mathrm{rms}$. This is much lower than the 12-nm-rms underside roughness of HFreleased poly $\left(585^{\circ} \mathrm{C}, 500 \mathrm{mT}\right.$ deposition) deposited on PSG [13].

We have successfully applied a carbon sacrificial layer to mold and release high aspect ratio polysilicon structures. As shown in Fig. 1, the carbon provides an extremely thin and conformal sacrificial layer, and consequently, the molded parts very closely resemble their molds, as shown in Figs. 2 and 9.

A couple of the failure modes encountered in our initial runs are shown in Fig. 8. Fig. 8(a) shows the effect of micropores in the carbon, through which polysilicon deposited, attaching the part to the mold. Most of these pores are around $0.1 \mu \mathrm{m}$ in diameter and do not result in enough force to actually bind the part into the mold, but larger ones may be a cause for our currently low yield.

A more significant problem lay in our molds, where accelerated undercut at convex corners led to a footing effect, making the mold larger at the bottom than at the neck constriction. With a thick sacrificial layer, the part might still have been able to be pulled out, but with the thin carbon layer, the footing was enough to prevent mold extraction. This problem can be solved by retuning the deep RIE etcher to eliminate the foot.
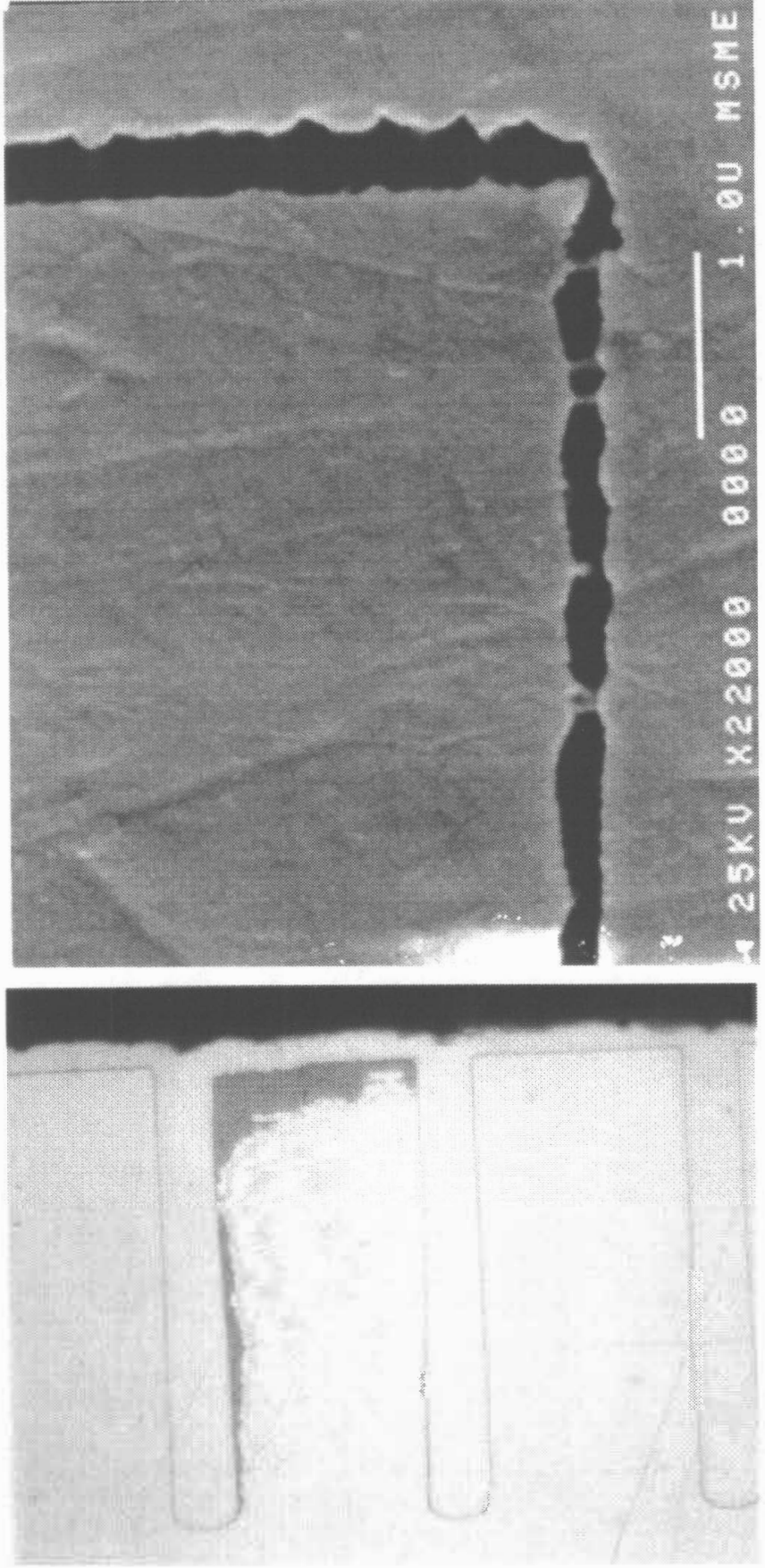

Figure 8. Failure modes in our recent Hexsil run. (a) Strands of polysilicon connect the part to the mold. These deposited through micropores in the carbon film. To prepare the sample for the SEM, the carbon was been etched back about a micron to make the interface more visible. (b) This cross section cuts right at the edge of a trench intersection. The convex corner presented by the intersection is undercut more rapidly, leading to the footing effect where the bottom of the trench is wider than the top.

\section{CONCLUSIONS}

Carbonized parylene has been demonstrated as a highly conformal, quickly etching sacrificial layer for Hexsil molding. Work remains to be done to optimize the process to minimize film shrinkage, reflow, and porosity. 
In Bernstein's earlier work with carbon sacrificial layers, it is claimed that a layer of silicon carbide remains on the polysilicon surface following oxidation [11]. We will investigate whether the polysilicon from our parylene process also leaves a silicon carbide coating, and if so, whether this coating is effective for reducing friction and wear.

We will also study the fracture strength of polysilicon fabricated and released in this process to see if any improvements result from elimination of the HF release. Finally, carbon does not necessarily have to be used as a replacement for oxide, but can be used as a complementary sacrificial layer alongside oxide since the methods used to etch one material do not affect the other. We are beginning investigation of microfabricated structures involving multiple sacrificial layers for progressive release of parts.

\section{ACKNOWLEDGEMENTS}

The authors thank Mike Smith at Specialty Coating Systems, Ontario, CA; and Xuan-Qi Wang and Prof. Y.C. Tai at the California Institute of Technology, Pasadena, CA, for providing parylene coatings.

In addition we wish to thank Jim Bustillo for deep-trench processing assistance; Ron Wilson and Sharon Tackaberry for help in obtaining SEM pictures; as well as Dr. Jonathon Kluth, Dr. Carlo Carrero, and Prof. Roya Maboudian for assistance in obtaining AFM and water surface contact angle measurements.

This material is based upon work supported under a National Science Foundation Graduate Fellowship.

\section{REFERENCES}

1. J. M. Bustillo, R. T. Howe, and R. S. Muller, "Surface micromachining for micro-electro-mechanical systems", to be published in Proc. IEEE, 1998.

2. C. G. Keller, Ph.D. Thesis, Dept. of Materials Science and Mineral Engineering, University of California at Berkeley, May 1998.

3. S. M. Sze, VLSI Technology, 2nd ed. McGraw-Hill, 1988.

4. C. G. Keller, R. T. Howe, Transducers '95, The 8th International Conference on Solid-State Sensors and Actuators, Vol. 1, June 1995, Stockholm, Sweden, pp. 99-102.

5. D. J. Monk, D. S. Soane, and R. T. Howe, J. Electrochem. Soc., 141, 1, 264-269 (1994).

6. R. Maboudian and R. T. Howe, J. Vac. Science and Tech. B, 15, 1-19, (1997).

7. T. A. Lober and R. T. Howe, IEEE Solid-State Sensors and Actuators Workshop, Hilton Head, S.C., June 6-9, 1988, pp. 59-62. 8. J. A. Walker, K. J. Gabriel, M. Mehregany, Proceedings IEEE MEMS-90, Napa Valley, Feb 11-14, 1990, pp. 56-59.

9. P. T. Jones, G. C. Johnson, R. T. Howe, Microelectromechanical Systems (MEMS) ASME 1996, DSC-Vol. 59, pp. 325-330.

10. T. Tsuchiya, O. Tabata, J. Sakata, Y. Taga, IEEE/ASME J. Micro Electro Mech. Systems, March, 1998, pp.106-113.

11. J. Bernstein, T.B. Kroger, J. of the Electrochemical Society: Solid-State Science and Technology, Aug, 1988, pp. 2086-2090.

12. G. M. Jenkins and K. Kawamura, Polymeric carbons carbon fibre, glass and char, 1976, pp.11-17.

13. M. R. Houston, Ph.D. thesis, Dept. of Chemical Engineering, University of California at Berkeley, 1996.
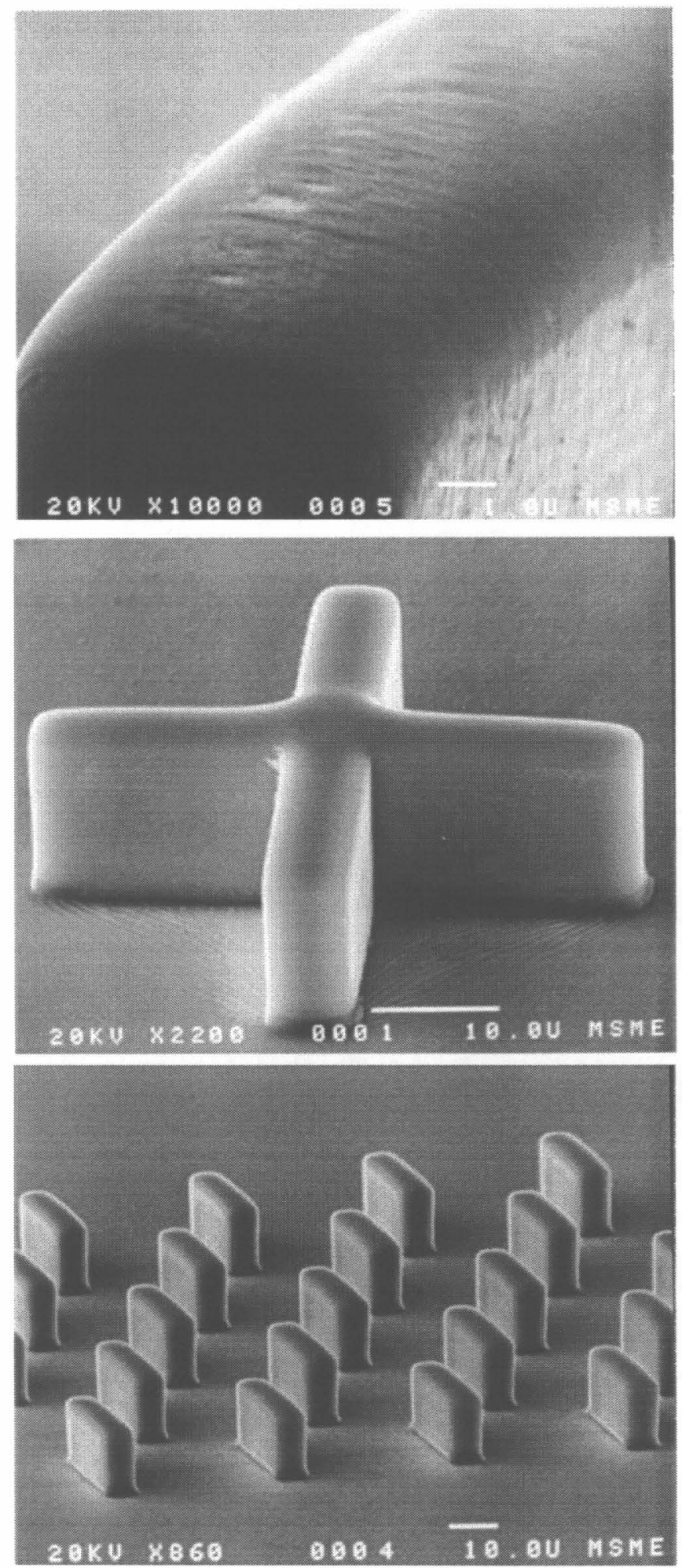

Figure 9. (a) A close-up view of the tip of a molded fin. This is formed at the bottom of the mold trench. (b) A molded Hexsil cross. (c) An array of molded fins. Note that the surface poly is intact and that no etch holes were used to release this entire sheet. 